\title{
Biological Assessment Pertumbuhan Lumut di Candi Borobudur pada Sisi Utara dan Selatan Lorong 2
}

\author{
Dandri Aly Purawijaya ${ }^{1} \&$ Adinda Gita Priyantika \\ Sekolah Ilmu dan Teknologi Hayati, Institut Teknologi Bandung \\ Email : daretoreal@gmail.com
}

\begin{abstract}
Abstrak : Penelitian biological assessment pada pertumbuhan lumut di Candi Borobudur ditujukan sebagai inisiasi penlitian untuk menentukan rumus hubungan antara pertumbuhan lumut dengan tingkat kerusakan candi. Penelitian dilakukan dengan mengambil sampel pada sisi utara dan sisi selatan lorong 2 Candi Borobudur. Pengambilan sampel dilakukan pada empat spot pada setiap sisi dengan pengulangan dua kali setiap spotnya. Sampel dari lapangan ditimbang kemudian dikeringkan dalam oven hingga berat konstan dan dibakar dalam furnace untuk memisahkan sisa partikel lumut dengan pasir. Berdasarkan data berat dilakukan konversi sehingga didapatkan nilai indeks konversi sebesar $0.00560274 \mathrm{x}$ $\mathrm{g} / \mathrm{cm}^{2}$ berdasarkan tutupan lumut terhadap massa pasir batuan yang terbawa oleh lumut. Berdasarkan nilai indeks, dapat disimpulkan bahwa lumut tidak menjadi ancaman yang berarti bagi keberlangsungan Candi Borobudur karena sedikitnya jumlah pasir yang terbawa oleh lumut ketika diambil dari batuan.
\end{abstract}

Kata Kunci : Biological Assessment, Candi Borobudur, Lumut, Lorong 2, Biodeteriorasi

\begin{abstract}
The biological assessment of Borobudur Temple mosses growth was an initial research to determine the correlation formula between mosses growth and building deteriorations. This research was conducted with samples collection from northern and southern parts of Borobudur Temple's Lorong 2. Samples were collected from four spots of each part and repeated two times for each spot. Samples were measured then dried using oven until the mass was constant. Samples were burned using furnace to separate organic masses and sand particles. Measured masses were converted and the conversion index was $0.00560274 \mathrm{x} \mathrm{g} / \mathrm{cm} 2$ based on mosses coverage and sand particle masses from the mosses substrate. Based on conversion index, it can be concluded that mosses do not possess a threat for Borobudur Temple because the sand particle masses that were eroded when the mosses were cleaned can be counted as few.
\end{abstract}

Kata Kunci : Biological Assessment, Borobudur Temple, Mosses, Lorong 2, Biodeterioration

\section{Pendahuluan}

Candi Borobudur merupakan monumen sejarah yang berada di Desa Borobudur, Kecamatan Borobudur, Kabupaten Magelang, Provinsi Jawa Tengah. Secara astronomis, Candi Borobudur terletak pada $7^{\circ} 36^{\prime} 28^{\prime \prime}$ LS dan 110 12'13" BT. Candi Borobudur terletak pada daerah dengan ketinggian 265 dpl. Batuan pada Candi Borobudur sebagian besar terdiri atas batuan andesit yang memiliki ciri berpori banyak. Pori yang banyak pada batuan andesit menyebabkan bervariasinya nilai porositas sehingga memungkinkan untuk tertampungnya air. Penampungan air pada pori-pori batuan andesit menyebabkan terbentuknya lingkungan yang mendukung untuk pertumbuhan mikroorganisme perintis dan menyebabkan terjadinya biodeteriorasi (Konservasi Borobudur, 2012; Kanaori et al., 2000; Buscot, 2000).

Biodeteriorasi batuan adalah proses perusakan batuan yang disebabkan oleh agen biologis yang disebut dengan biodeteriogen. Biotedeteriogen dapat menyebabkan kerusakan secara langsung ataupun secara tidak langsung. Agen biodeteriorasi antara lain adalah jamur, algae, lumut, dan bakteri (Kumar \& Kumar, 1999).

Lumut merupakan organisme peralihan yang berada pada kingdom plantae dengan karakteristik khas tidak memiliki jaringan vaskuler dan tidak memiliki akar sejati namun memiliki rhizoid. Lumut merupakan organisme autotrof dengan memiliki pigmen klorofil dan karotenoid. Lumut merupakan organisme yang hidup pada daerah lembab dan umumnya hidup bersimbiosis dengan organisme lain seperti fungi dan alga. Lumut merupakan organisme yang terdiri atas tiga divisi yang terdiri atas Bryophyta, lumut hati, dan lumut tanduk. Lumut merupakan organisme yang memerlukan daerah berair karena lumut memerlukan air dalam siklus reproduksinya untuk membantu proses fertilisasi. Lumut sendiri memiliki fungsi sebagai pembangun tanah untuk menyiapkan lahan bagi pertumbuhan organisme lain. (Kumar \& Kumar, 1999; Richardson, 2010; Peck \& Muir, 2001; Bernard \& Buck, 2004).

Biological Assessment merupakan salah satu upaya untuk mendokumentasikan efek lingkungan terhadap 
agensia biologis yang dianggap terancam sekaligus menilai efek dari agen biologis tersebut terhadap habitatnya (Scott \& Hainess, 2008). Adapun beberapa substrat yang menjadi habitat bagi lumut adalah batuan, tanah mineral, tanah asam, sisi sungai, tanah berhumus, batang kayu, ranting kayu, dan lain-lain (Pojar \& MacKinnon, 1994). Dalam melakukan Biological Assessment, terdapat beberapa tahapan dan hal-hal yang harus diperhatikan seperti ruang lingkup penelitian, kondisi fisik dan biologis dari ruang lingkup yang diteliti, identifikasi spesies, identifikasi habitat dari spesies, dan deskripsi tindakan yang dapat diambil untuk spesies tersebut (USFWS, 2012). Biological Assessment terkait lumut masih jarang sekali untuk dilakukan karena lumut dianggap sebagai organisme yang memiliki status berlimpah sehingga dianggap tidak perlu dilakukan assessment. Biological Assessment umum dilakukan pada spesies-spesies yang dianggap terancam kepunahan (Scott \& Hainess, 2008).

\section{Tujuan Penelitian}

Penelitian biological assessment pada pertumbuhan lumut di Candi Borobudur ditujukan sebagai inisiasi penlitian untuk menentukan rumus hubungan antara pertumbuhan lumut dengan tingkat kerusakan candi

\section{Metode}

Pengambilan sampel dilakukan di lorong 2 Candi Borobudur dengan asumsi lorong 2 dapat mewakili data pada loronglorong di bawahnya dan di atasnya karena lorong 2 berada di ketinggian tengah Candi Borobudur. Pengambilan sampel dilakukan pada bulan Juni 2012. Pada proses pengambilan sampel dilakukan 2 kali pengulangan pada delapan titik yang ditentukan.

\section{Pengambilan sampel di Lapangan.}

Pada lorong 2 ditentukan delapan titik pengambilan sampel dan dibuat plot $10 \times 10 \mathrm{~cm}$ pada masing-masing tempat. Kemudian, lumut dan mineral yang melapuk diambil dan dimasukkan ke kantong klip. Pada saat pengambilan data dilakukan pengukuran mikroklimat sebagai parameter sekunder.

\section{Pengukuran Biomassa dan Mineral Batuan.}

Biomassa lumut dan mineral batuan dipisahkan menggunakan metode penyaringan. Kemudian biomassa lumut dikeringkan dalam oven pada suhu $60{ }^{\circ} \mathrm{C}$ hingga beratnya tetap dan partikel pasir disaring menggunakan kertas Whatman no. 60. Partikel pasir kemudian dibakar dalam furnace pada suhu $900{ }^{\circ} \mathrm{C}$. Terakhir berat dari biomassa lumut dan partikel pasir ditimbang untuk dibandingkan menghitung indeks konversi tutupan lumut terhadap jumlah pasir yang dibawa ketika lumut diambil dari batuan.

Metode Perhitungan. Signifikansi kerusakan yang ditimbulkan oleh lumut dilihat melalui angka indeks. Perhitungan indeks dilakukan dengan rumus :

\section{Berat pasir//Biomassa Lumut}

\section{Index $=\frac{\text { Luas Permukaan Plot }}{}$}

Rumus perhitungan indeks diajukan untuk

Tabel 1. Berat Lumut dan Berat Pasir

\begin{tabular}{|c|c|c|c|c|c|c|}
\hline Spot & $\begin{array}{l}\text { Berat } \\
\text { Lumut }\end{array}$ & $\begin{array}{c}\text { Berat } \\
\text { lumut } / \mathrm{cm}^{2}\end{array}$ & $\begin{array}{c}\text { Berat } \\
\text { Pasir } \\
\text { (g) }\end{array}$ & $\begin{array}{l}\text { Luas } \\
\left(\mathrm{cm}^{2}\right)\end{array}$ & $\begin{array}{l}\text { Perbandingan } \\
\text { lumut/pasir }\end{array}$ & Index $\left(/ \mathrm{cm}^{2}\right)$ \\
\hline $\begin{array}{l}\text { Lt } 4 \text { selatan bidang a } \\
\text { pengulangan } 1\end{array}$ & 0,0519 & 0,001384 & 0,0008 & 37,5 & 64,875 & 1,73 \\
\hline $\begin{array}{l}\text { Lt } 4 \text { selatan bidang a } \\
\text { pengulangan } 2\end{array}$ & 0,0127 & 0,00127 & 0,0658 & 10 & 0,19300912 & 0,019301 \\
\hline $\begin{array}{l}\text { Lt } 4 \text { selatan bidang a } \\
\text { pengulangan } 3\end{array}$ & 0,0221 & 0,0027625 & 0,0101 & 8 & 2,18811881 & 0,273515 \\
\hline $\begin{array}{l}\text { Lt } 4 \text { selatan bidang } \mathrm{c} \\
\text { pengulangan } 1\end{array}$ & 0,0088 & 0,0002958 & 0,0071 & 29,75 & 1,23943662 & 0,041662 \\
\hline $\begin{array}{l}\text { Lt } 4 \text { selatan bidang } c \\
\text { pengulangan } 2\end{array}$ & 0,0166 & 0,0027667 & 0,0021 & 6 & 7,9047619 & 1,31746 \\
\hline $\begin{array}{l}\text { Lt } 4 \text { selatan bidang } c \\
\text { pengulangan } 3\end{array}$ & 0,029 & 0,0024167 & 0,0043 & 12 & 6,74418605 & 0,562016 \\
\hline $\begin{array}{l}\text { Lt } 4 \text { selatan bidang } \mathrm{h} \\
\text { pengulangan } 1\end{array}$ & 0,0246 & 0,0008786 & 0,00723 & 28 & 3,40248963 & 0,121517 \\
\hline $\begin{array}{l}\text { Lt } 4 \text { selatan bidang } \mathrm{h} \\
\text { pengulangan } 2\end{array}$ & 0,0115 & 0,0005476 & 0,0278 & 21 & 0,41366906 & 0,019699 \\
\hline $\begin{array}{l}\text { Lt } 4 \text { selatan bidang } \mathrm{h} \\
\text { pengulangan } 3\end{array}$ & 0,012 & 0,0006667 & 0,0126 & 18 & 0,95238095 & 0,05291 \\
\hline $\begin{array}{l}\text { Lt } 4 \text { selatan bidang } j \\
\text { pengulangan } 1\end{array}$ & 0,0074 & 0,000185 & 0,4951 & 40 & 0,01494648 & 0,000374 \\
\hline $\begin{array}{l}\text { Lt } 4 \text { selatan bidang } j \\
\text { pengulangan } 2\end{array}$ & 0,0474 & 0,00395 & 0,019 & 12 & 2,49473684 & 0,207895 \\
\hline $\begin{array}{l}\text { Lt } 4 \text { selatan bidang } i \\
\text { pengulangan } 3\end{array}$ & 0,0153 & 0,00102 & 0,039 & 15 & 0,39230769 & 0,026154 \\
\hline $\begin{array}{l}\text { Lt } 4 \text { utara bidang a } \\
\text { pengulangan } 1\end{array}$ & 0.0100 & 0.106951872 & 0.0935 & 9 & 0.106951872 & 0.011884 \\
\hline $\begin{array}{l}\text { Lt } 4 \text { utara bidang a } \\
\text { pengulangan } 2\end{array}$ & 0.0088 & 1.571428571 & 0.0056 & 16 & 1.571428571 & 0.098214 \\
\hline $\begin{array}{l}\text { Lt } 4 \text { utara bidang } \mathrm{c} \\
\text { pengulangan } 1\end{array}$ & 0.1156 & 5.989637306 & 0.0193 & 12 & 5.989637306 & 0.499136 \\
\hline $\begin{array}{l}\text { Lt } 4 \text { utara bidang } \mathrm{c} \\
\text { pengulangan } 2\end{array}$ & 0.0157 & 0.356818182 & 0.044 & 12 & 0.356818182 & 0.029735 \\
\hline $\begin{array}{l}\text { Lt } 4 \text { utara bidang } c \\
\text { pengulangan } 3\end{array}$ & 0.0117 & 1.258064516 & 0.0093 & 30 & 1.258064516 & 0.041935 \\
\hline $\begin{array}{l}\text { Lt } 4 \text { utara bidang } \mathrm{h} \\
\text { pengulangan } 1\end{array}$ & 0.0293 & 4.966101695 & 0.0059 & 6 & 4.966101695 & 0.827684 \\
\hline $\begin{array}{l}\text { Lt } 4 \text { utara bidang } \mathrm{h} \\
\text { pengulangan } 2\end{array}$ & 0.0121 & 0.828767123 & 0.0146 & 8 & 0.828767123 & 0.103596 \\
\hline $\begin{array}{l}\text { Lt } 4 \text { utara bidang } h \\
\text { pengulangan } 3\end{array}$ & 0.0011 & 0.016717325 & 0.0658 & 30 & 0.016717325 & 0.000557 \\
\hline $\begin{array}{l}\text { Lt } 4 \text { utara bidang } \mathrm{j} \\
\text { pengulangan } 1\end{array}$ & 0.0045 & 3 & 0.0015 & 10 & 3 & 0.3 \\
\hline $\begin{array}{l}\text { Lt } 4 \text { utara bidang } j \\
\text { pengulangan } 2\end{array}$ & 0.0492 & 3.617647059 & 0.0136 & 30 & 3.617647059 & 0.120588 \\
\hline $\begin{array}{l}\text { Lt } 4 \text { utara bidang } \mathrm{j} \\
\text { pengulangan } 3\end{array}$ & 0.1075 & 2.095516569 & 0.0513 & 12 & 2.095516569 & 0.174626 \\
\hline
\end{tabular}


melakukan pendekatan kerusakan batuan oleh lumut. Rata-rata index dikalikan dengan data biomassa lumut/ $\mathrm{cm}^{2}$. Hasilnya berupa konstanta jumlah mineral pasir yang terlapukkan per biomassa lumut $/ \mathrm{cm}^{2}$. Konstanta dapat digunakan untuk menghitung jumlah pasir yang terlapukkan berdasarkan coverage lumut pada keseluruhan blok.

Konstanta $=$ Rata - rata Index $\times$ Rata-rata $\frac{\text { Biomassa lumut }}{\text { Luas Permukaan }}$

\section{Hasil Pengamatan}

Data-data pada Tabel 1 diuji menggunakan analisis statistik ANOVA untuk melihat kecenderungan dari data. Nilai Signifikansi dari hasil uji statistik untuk index ( $p>0.05)$ menunjukkan bahwa data tiap plot tidak berbeda secara signifikan.

Uji statistik juga dilakukan untuk parameter mikroklimat dan hasil uji statistik menunjukkan delapan titik pengambilan sampel tidak memiliki perbedaan yang signifikan $(\mathrm{p}>0.05)$ terkait parameter mikroklimat (Tabel 2).

Rata-rata Index dari Tabel 1 dikalikan dengan nilai rata-rata biomassa lumut $/ \mathrm{cm}^{2}$, kemudian didapatkan konstanta. Konstanta tersebut dapat dikalikan dengan luas bidang tutupan (coverage) untuk mendapatkan mineral pasir yang terbawa oleh biomassa lumut pada suatu blok. Konstanta yang didapatkan adalah $0.00560274 \mathrm{x} \mathrm{g} / \mathrm{cm}^{2}$.

Data coverage lumut didapatkan dengan cara mengukur luas tutupan lumut pada blok tempat pengambilan sampel sehingga didapatkan data seperti pada Tabel 3. Rata-rata nilai coverage adalah 33\%, dengan coverage paling rendah 15\% dan coverage paling tinggi 60\%. Hasil pembulatan ke atas rata-rata mineral batuan yang terbawa pada blok-blok yang diukur di bidang selatan adalah 0,1 gram sedangkan pada bidang utara adalah 0,2 gram.

\section{Diskusi}

Hasil penelitian menunjukkan bahwa biomassa lumut lebih dipengaruhi oleh kelembaban batu dibandingkan dengan kelembaban udara. Jika dibandingkan, nilai biomassa lumut per $\mathrm{cm}^{2}$ sebanding dengan kelembaban batu. Sedangkan, ketika data biomassa lumut per $\mathrm{cm}^{2}$ dibandingkan dengan kelembaban udara serta intensitas, nilai indeks tidak selalu berbanding lurus dengan nilai kedua faktor tersebut. Oleh karena itu dapat disimpulkan pada percobaan ini, kelembaban batu lebih memberikan pengaruh secara langsung, sementara kelembaban udara tidak memberikan pengaruh langsung. Meskipun demikian, tingkat kelembaban batu dipengaruhi oleh intensitas cahaya dan kelembaban udara sehingga secara tidak langsung, intensitas cahaya dan kelembaban udara berpengaruh terhadap biomassa lumut (Ryan et al., 2012). Hal ini dapat dijadikan sebagai pertimbangan dalam pensiasatan faktor lingkungan dalam pengontrolan pertumbuhan lumut.

Data hasil penelitian juga menunjukkan bahwa berat mineral batuan 
Tabel 3. Konversi Partikel Pasir Setiap Spot Pengamatan

\begin{tabular}{|c|c|c|c|c|}
\hline Spot & $\begin{array}{l}\text { Luas Blok } \\
\left(\mathrm{cm}^{2}\right)\end{array}$ & Coverrge & $\begin{array}{l}\text { Luas coverage } \\
\qquad\left(\mathrm{cm}^{2}\right)\end{array}$ & Partikel Pasir (g) \\
\hline $\begin{array}{l}\text { Lt } 4 \text { selatan bidang a } \\
\text { pengulangan } 1\end{array}$ & 690 & $20 \%$ & 119,7 & 0,054294 \\
\hline $\begin{array}{l}\text { Lt } 4 \text { selatan bidang a } \\
\text { pengulangan } 2\end{array}$ & 560 & $15 \%$ & 84 & 0,038101 \\
\hline $\begin{array}{l}\text { Lt } 4 \text { selatan bidang a } \\
\text { pengulangan } 3\end{array}$ & 630 & $19 \%$ & 138 & 0,062595 \\
\hline $\begin{array}{l}\text { Lt } 4 \text { sel atan bidang } c \\
\text { pengulangan } 1\end{array}$ & 900 & $50 \%$ & 450 & 0,204114 \\
\hline $\begin{array}{l}\text { Lt } 4 \text { sel atan bidang } c \\
\text { pengulangan } 2\end{array}$ & 820 & $40 \%$ & 273,2 & 0,12392 \\
\hline $\begin{array}{l}\text { Lt } 4 \text { sel atan bidang } c \\
\text { pengulangan } 3\end{array}$ & 600 & $25 \%$ & 150 & 0,068038 \\
\hline $\begin{array}{l}\text { Lt } 4 \text { selatan bidang } h \\
\text { pengulangan } 1\end{array}$ & 580 & $40 \%$ & 232 & 0,105232 \\
\hline $\begin{array}{l}\text { Lt } 4 \text { sel at an bidang } \mathrm{h} \\
\text { pengulangan } 2\end{array}$ & 380 & $20 \%$ & 76 & 0,034473 \\
\hline $\begin{array}{l}\text { Lt } 4 \text { selat an bidang } h \\
\text { pengulangan } 3\end{array}$ & 609,5 & $50 \%$ & 304,75 & 0,138231 \\
\hline $\begin{array}{l}\text { Lt } 4 \text { selatan bidang } j \\
\text { pengulangan } 1\end{array}$ & & $58 \%$ & 418,76 & 0,189944 \\
\hline $\begin{array}{l}\text { Lt } 4 \text { sel atan bidang } \mathrm{j} \\
\text { pengulangan } 2\end{array}$ & 551 & $20 \%$ & 110,2 & 0,049985 \\
\hline $\begin{array}{l}\text { Lt } 4 \text { sel atan bidang } j \\
\text { pengulangan } 3\end{array}$ & 760 & $38 \%$ & 288,8 & 0,130996 \\
\hline $\begin{array}{l}\text { Lt } 4 \text { utara bidang a } \\
\text { pengulangan } 1\end{array}$ & 327.75 & $60 \%$ & 196.65 & 1.311553 \\
\hline $\begin{array}{l}\text { Lt } 4 \text { utara bidang a } \\
\text { pengulangan } 2\end{array}$ & 429 & $35 \%$ & 150.15 & 1.001422 \\
\hline $\begin{array}{l}\text { Lt } 4 \text { utara bidang } \mathrm{c} \\
\text { pengulangan } 1\end{array}$ & 641.25 & $20 \%$ & 128.25 & 0.855361 \\
\hline $\begin{array}{l}\text { Lt } 4 \text { utara bidang } \mathrm{c} \\
\text { pengulangan } 2\end{array}$ & 290.56 & $15 \%$ & 43.584 & 0.290683 \\
\hline $\begin{array}{l}\text { Lt } 4 \text { utara bidang } \mathrm{c} \\
\text { pengulangan } 3\end{array}$ & 300 & $35 \%$ & 105 & 0.700295 \\
\hline $\begin{array}{lll}\text { Lt } 4 \text { utara bidang } & h \\
\text { pengulangan } 1 & \end{array}$ & 459.2 & $15 \%$ & 68.88 & 0.459394 \\
\hline $\begin{array}{l}\text { Lt } 4 \text { utara bidang } h \\
\text { pengulangan } 2\end{array}$ & 534.75 & $30 \%$ & 160.425 & 1.069951 \\
\hline $\begin{array}{l}\text { Lt } 4 \text { utara bidang } h \\
\text { pengulangan } 3\end{array}$ & 534.75 & $30 \%$ & 160.425 & 1.069951 \\
\hline $\begin{array}{l}\text { Lt } 4 \text { utara bidang } j \\
\text { pengulangan } 1\end{array}$ & 303.02 & $15 \%$ & 45.453 & 0.303148 \\
\hline $\begin{array}{l}\text { Lt } 4 \text { utara bidang } j \\
\text { pengulangan } 2\end{array}$ & 293 & $40 \%$ & 117.2 & 0.781663 \\
\hline $\begin{array}{l}\text { Lt } 4 \text { utara bidang } j \\
\text { pengulangan } 3\end{array}$ & 293 & $40 \%$ & 117.2 & 0.781663 \\
\hline
\end{tabular}

bagian selatan. Biomassa lumut tidak selalu menunjukkan kedalaman dan coverage dari rhizoid karena terdapat kemungkinan rhizoid di dalam memiliki coverage yang lebih besar dibandingkan dengan coverage pada permukaan. Dengan demikian, ada baiknya untuk penelitian lebih lanjut dilakukan perbandingan antara biomassa dengan coverage permukaan dan coverage rhizoid.

Faktor kedua adalah kelembaban yang ditimbulkan oleh lumut. Meskipun biomassa lumut kecil, jika kandungan air pada lumut tinggi maka kelembaban pada batuan yang akan menjadi tinggi. Tingginya kelembaban pada batuan menyebabkan mineral batuan yang dapat terdegradasi menjadi lebih banyak. Proses pelapukan oleh kelembaban dapat terjadi karena terjadinya reaksi hidrasi pada komponen mineral penyusun batuan.

Meskipun metode yang digunakan sudah dapat menjawab tujuan, metode masih dapat

yang terbawa oleh lumut tidak selalu berbanding lurus dengan biomassa lumut. Pada nilai berat mineral batuan tertinggi nilai biomassa lumut justru cukup rendah jika dibandingkan dengan nilai lainnya. Hal tersebut dapat dijelaskan dengan faktor-faktor dalam pertumbuhan lumut yang mempengaruhi kerusakan batu.

Faktor pertama adalah kedalaman rhizoid, semakin dalam rhizoid maka semakin besar kerusakan pada batuan yang ditimbulkan oleh lumut. Rhizoid lumut yang tumbuh pada batuan candi dapat menembus hingga 2-3 milimeter ke dalam batu (Gunawan et al., 2007). Oleh karena itu partikel pasir akan terbawa oleh rhizoid lumut tersebut dan menyebabkan kerusakan pada batuan. Berdasarkan analisis hasil percobaan terbukti bahwa lumut rata-rata dapat mengambil partikel pasir sebanyak $0,3 \mathrm{x}$ dari biomassanya per $\mathrm{cm}^{2}$ pada dinding dikembangkan terkait beberapa faktor. Faktor pertama adalah pengambilan data menggunakan cara mekanik. Proses pengambilan sampel sangat mempengaruhimineral batuan yang terbawa karena pengambilan sampel secara mekanis diduga akan menyebabkan pengikisan secara mekanis pada batuan substrat tumbuh lumut. Pengikisan secara mekanis akan menyebabkan bertambahnya berat mineral pasir sehingga mineral pasir yang terkoleksi tidak hanya dari hasil perusakan lumut. Kedua adalah proses penyaringan. Metode pemisahan biomassa dan mineral batuan dengan cara penyaringan masih belum dapat memisahkan biomassa dan partikel pasir secara sempurna. Walaupun telah digunakan furnace untuk menghilangkan materi organik dari mineral batu, hasil yang didapatkan masih belum tepat karena pada proses penyaringan diduga terdapat partikel yang menempel pada saringan 
dan terbuang. Hal ini sangat mungkin terjadi karena massa yang digunakan sangatlah kecil (rata-rata $<1$ gram) Terakhir, metode belum dapat membedakan kerusakan yang hanya ditimbulkan oleh lumut dan organisme sejenis lainnya. Lumut merupakan organisme perintis sehingga tidak terlepas kemungkinan adanya organisme lain yang sudah mulai hidup dan mempengaruhi biomassa yang terkoleksi sedangkan organisme lain tidak berkontribusi pada pelapukan batuan.

\section{Kesimpulan}

Berdasarkan hasil penelitian, disimpulkan bahwa metode pengambilan sampel masih perlu diperbaiki

\section{Daftar Pustaka}

Atlas RM, Bartha R. 1987. Microbial Ecology: Fundamental and Application. Benjamin Cummings, San Fransisco

Bernard, G. \& W. R. Buck. 2004. Systematic of the Bryophyta (Mosses) : From Molecules to a Revised Classification. Monographs in Systematic Botany. 98 : $205-239$

Budiharji, Eko (ed). 1997. Preservation and Conservation of Cultural Heritage in Indonesia. Gadjah Mada University Press, Jogjakarta. Hal 31

Buscot, F. 2000. Microorganisms in Soils : Roles in Genesis and Functions. Berlin: Springerlink. p 65-66

Doehne, Edan Clifford E Price. 2010. Stone Conservation, An Overview of Current Research. Getty Publication, Los Angeles.

Friedman D. 2012. Inspectapedia: Online Encyclopedia.

Diakses dari http://inspectapedia.com. Pada 20 Juni 2012

Gunawan, A., Kurniadi, R. \& W. Setiyono. 2007. Laporan Studi Metode Pembersihan Lumut dengan Pemanasan. Magelang : Balai Konservasi Peninggalan Borobudur

Kanaori, Y., Anaka, K. \& M. Chigira. 2000. Engineering Geological Advances in Japan for the New Millenium. Amsterdam : Elsevier. p 315

Konservasi Borobudur. 2012. Candi Borobudur. Diakses dari http://konservasiborobudur.org/ dengan cara pengambilan sampel dengan cara selain cara mekanik, pemisahan partikel pasir dan biomassa untuk sampel dengan massa yang sedikit, dan metode pengkoleksian yang memang hanya mengkoleksi lumut dengan tidak mengkoleksi organisme lain. Berdasarkan hasil penelitian diperoleh indeks konversi coverage lumut dengan perkiraan massa pasir yang terbawa adalah $0.00560274 \mathrm{x} \mathrm{g} / \mathrm{cm}^{2}$. Berdasarkan nilai indeks konversi, lumut tidak menjadi faktor pengancam bagi kehancuran Candi Borobudur karena sedikitnya massa pasir yang dibawa bila dibandingkan keseluruhan massa pasir Candi Borobudur.

v3/20110104110/statis/candi-borobudur.html pada 6 Juni 2012

Kumar, R. \& A. V. Kumar. 1999. Biodeterioration of Stone in Tropical Environments : An Overview. New York : Getty Conservation Institute

Peck, J. E. \& P. S. Muir. 2001. Estimating the Biomass of Harvestable Epiphytic Moss in Central West Oregon. Northwest Science. 75 (2) : 99 - 106

Pojar \& MacKinnon. 1994. Plants of Pacific Northwest Coast. Vancouver : Lone Pine Publishing

Richardson, R. 2010. The Bryophytes. Diakses dari http:/ / scidiv.bellevuecollege.edu/rkr/botany110/ lectures/bryophytes.html pada 6 Juni 2012

Ryan K, Talaber A, Heimbuch M, Sood M. 2012. Effect of Light Avalaibility and Humidity Gradient on Anomodon attenuatus. Diakses dari : https:// netfiles.uiuc.edu/kcryan2/shared/1.html pada 20 Juni 2012

Scott, A. \& K. Haines. 2008. Invasive Plants Biological Assessment. Diakses dari http://www. fs.usda.gov/Internet/FSE_DOCUMENTS/ stelprdb5201682.pdf pada 7 Juni 2012

Swastikawati, Ari dk. 2001. Studi Karakteristik Pertumbuhan Moss dan Algae Terhadap

Kelestarian Candi Batu. Balai Konservasi

Peninggalan Borobudur, Magelang

Swietlik W, Barbour M, Yoder C. 2003. Introduction to Biological Assessment and Criteria in: 
National Biological Assessment and Workshop.

Idaho, USA, Mar 31

April 4, 2003. p.12-16

Tiano, Piero. 2002. Biodegradation of Cultural Heritage:

Decay Control and Mechanism in:Cause of

Degradation and Conservation Method in

Historical Site. Firenze, Italia.

Urzi, Clara.2012. Notes On: Biodeterioration of Stone Related to Cultural History. International

Biodeterioration and Biodegradation society. Diakses dari www.ibbsonline.org pada 4 Juni 2012
USFWS. 2012. Guidance for Preparing a Biological Assessment. Diakses dari http://www.fws. gov/midwest/endangered/section $7 / \mathrm{pdf} /$ BAGuidance.pdf pada 7 Juni 2012

Wigginton MJ. 2006. Hypopterigiaceae. Diakses dari http://www.dulwichrunners.org.uk/gba/hypo. htm\#hypopterygium. Pada 20 Juni 2012 